\title{
Forest Fire Risk Assessment Based on Ecological and Economic Value - Take Yunnan Province as an Example \\ Chenxue Gao ${ }^{1,2}$ Ming Wang ${ }^{1,2, *}$
}

\author{
${ }^{1}$ State Key Laboratory of Earth Surface Processes and Resource Ecology (Beijing Normal University), Beijing \\ 100875, China \\ ${ }^{2}$ Academy of Disaster Reduction and Emergency Management, Ministry of Civil Affairs \& Ministry of Education, \\ Beijing 100875, China
}

\section{基于生态与经济价值的森林火灾风险评估 以云南省为例 高晨雪 $^{1,2}$ 汪明 ${ }^{1,2, *}$ \\ ${ }^{1}$ 地表过程与资源生态国家重点实验室(北京师范大学), 北京 100875, 中国 ${ }^{2}$ 民政部/教育部减灾与应急管理研究院, 北京 100875 , 中国}

\begin{abstract}
Taking ecological and economic value of forest into consideration during forest fire risk assessment could provide a scientific reference for integrated risk governance. Machine learning was combined with event simulation to implement fire risk assessment based on ecological and economic value of Yunnan forest. From this study, we draw the following conclusions: (1) The forest fire susceptibility can effectively improve the simulated events allocation process. (2) Spatial variation of forest fire risk is caused by wildfire susceptibility, unit area and gross value of forest. This may further contribute to differentiated risk response planning. (3) Results of this paper could provide references for Yunnan forest fire insurance practice.
\end{abstract}

Keywords: forest fire; risk assessment; wildfire susceptibility; ecological and economic value

*通讯作者: wangming@bnu.edu.cn

\section{摘要}

将森林生态与经济价值加入林火风险评估中, 能够为 林火风险管理提供科学的依据。本文选择云南为研究 区, 将机器学习与事件仿真结合, 实现了云南森林基 于生态与经济价值的火灾风险评估。研究得到以下结 论: (1) 林火敏感性能够有效改进林火仿真事件的 分配; (2) 林火敏感性、森林单元面积、森林总价 值共同作用导致了林火风险的空间分异, 分析三方面 因素的作用, 有助于差异化林火风险应对方案的制 定; (3) 文章结果能够为云南森林火灾保险实践提 供参考和借鉴。

关键词: 森林火灾; 风险评估; 森林火灾敏感性; 生 态与经济价值

1. 引言

森林是陆地生态系统的主体, 其多样的生态功能 为人类生存发展提供了环境保障。林业产业是规模最 大的绿色经济体, 能够在社会经济发展中提供多种用 途的林木、林果产品、休闲场所等。森林火灾是森林 三大自然灾害之首, 林火灾害发生将为林业产业带来 巨大的经济损失并严重破坏森林生态系统的生态服 务功能。近些年受到人类活动、厄尔尼诺现象频发等 
Risk Analysis and Crisis Response in Big Data Era (RAC-16)

因素影响, 全球气候变化加剧, 森林火灾活动更加频 繁 ${ }^{[1]}$, 从而增加了林火风险。中国目前已成为世界上 森林资源增长最快的国家, 森林资源总量位居世界前 列, 但森林覆盖率和人均森林面积仍远低于全球平均 水平, 林业发展和生态安全压力仍然巨大。进行准确 全面的林火风险评估, 有助于制定适宜的防火措施及 政策、降低森林火灾损失, 对于缓解森林生态压力、 发展可持续林业也有重要意义。

北美地区在林火风险评估方面的研究较为丰富, 由于国内林火风险评估开始较国外晚, 大多数评估工 作是结合我国森林所处的环境特点, 应用已有模型对 其进行借鉴或改进。现有的林火评估方法主要包括林 火预测模型和火灾蔓延模型。林火预测模型多需要基 于已有历史数据直接预测, 或是根据相关解释变量构 建预测模型。这类模型往往依赖于大量样本数据, 并 对样本比例平衡有较高要求。林火蔓延仿真模型受限 于其对起火点设定和环境变量数据的详实程度有较 高要求, 因而被认为更适宜在区域尺度使用 ${ }^{[2]}$ 。林火 风险评估的结果通常是如风险等级的定性、半定量结 果 ${ }^{[3]}$ ，以及林火发生概率、发生次数、受害面积等的 定量风险表达 ${ }^{[4,5]}$, 而并没有对于森林重要的生态、 经济价值的火灾风险给出评价。

云南地处我国西南地区, 是我国四大重点林区之 一, 既是重要的森林资源富集地，同时也是森林火灾
的重灾区。近年来, 随着全球气候变化, 云南省增温 和旱情有增多加剧的趋势, 火灾风险大大增加。因此, 对于云南进行全面的森林火灾风险评估十分必要, 是 进行全国森林火灾风险评估的重要组成部分。

因此, 本文选择云南文研究区, 将机器学习与蒙 特卡洛仿真结合, 将随机森林得到的林火敏感性用于 改进仿真事件分配过程, 并首次尝试将量化的林生态 与经济价值作为林火风险评估的表达, 最终结合生态 价值期望损失、经济价值期望损失和火灾易发性三方 面的森林火灾风险评估结果, 既能展示森林火灾风险 的区域性差异, 又能体现林火期望损失的相对大小是 由哪一方面作为主导, 从而为林火风险管理政策、防 灾减灾措施的实施提供参考, 有针对性的进行林火防 控工作。

\section{2. 研究方法框架}

本文主要包括四个主要步骤: 森林单元数字化、 森林生态与经济价值估算、林火事件仿真分配、林火 风险评估。如图1所示。本文使用的云南森林单元基 础数据是通过对第八次全国森林清查结果 (2009-2014)进行数字化得到的, 包括人工和天然的针 叶林、阔叶林、针阔混交林和竹林共八类。风险评估 中价值估算空间分辨率为 $1 \mathrm{~km}$ ，时间统一至2014年。

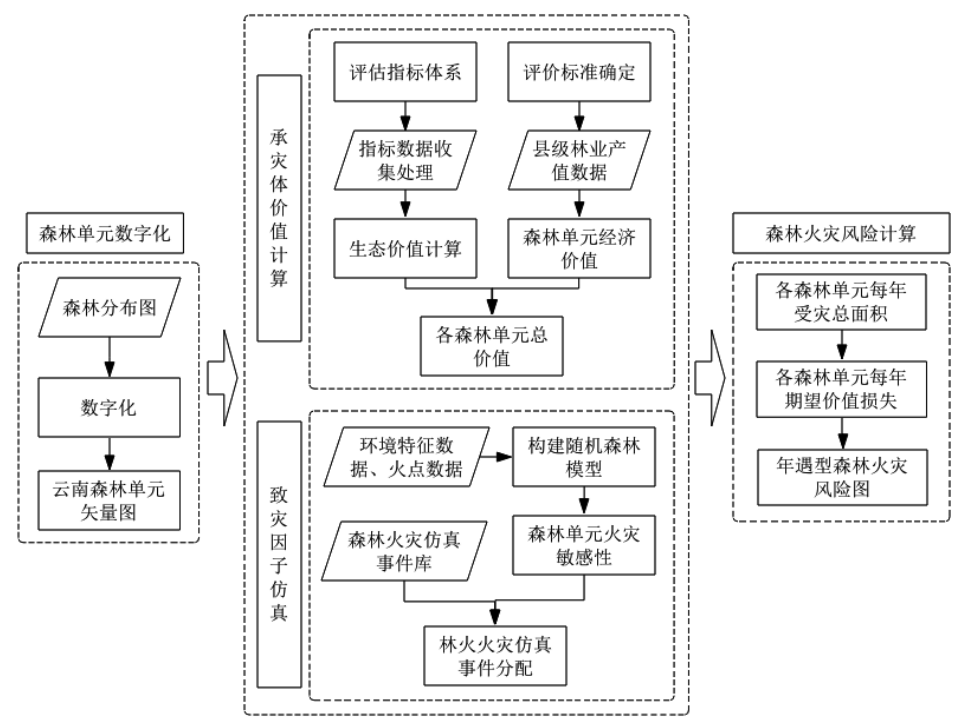

图 1. 森林火灾评估流程图 
Risk Analysis and Crisis Response in Big Data Era (RAC-16)

\section{3. 森林价值计算}

\section{1. 森林生态价值计算}

文章在评估森林生态价值时, 以替代市场法为 主, 主要借鉴我国《森林生态系统服务功能评估规范》 ${ }^{[6]}$ (以下简称《规范》) 中给出的森林生态系统服务 功能评估指标体系, 结合指标数据的可获得性以及可 靠性, 建立了如图2的灾前云南森林生态价值估算指 标体系。其中涵养水源、保育土壤、积累营养物、净 化大气环境及生物多样性保护价值均以《规范》中的 估算方法为参照, 对于固碳释氧价值, 则使用集成生 物圈模拟器IBIS 计算出的云南森林单元内单位面积 植被碳库和土壤有机碳库, 将其乘以碳税率进行计 算。《规范》中没有提供游㮩价值的科学计算公式, 文章使用以下方法流程实现对森林单元游悡价值的 估算:

1）根据云南省林业厅发布的云南省森林公园 基本信息获取云南森林公园名录;

2) 在Google Earth软件中输入公园信息以确定 公园位置, 将其经纬度点作为森林公园中心位置点;

3) 将位置点文件导入 ArcGIS软件，并选取 $15 \mathrm{~km}$ 范围内所涉及到的森林单元 (根据相关研究中 野外旅游可达旅游距离进行估计), 将这些单元作为 潜在的可带来林业相关游悡收入的森林单元;

4) 从 《中国林业统计年鉴》获取云南林业旅 游与休闲产业收入值;

5) 将该年收入值平均分配到所选取的森林单 元总面积中, 从而估算出单位面积森林游悡价值。

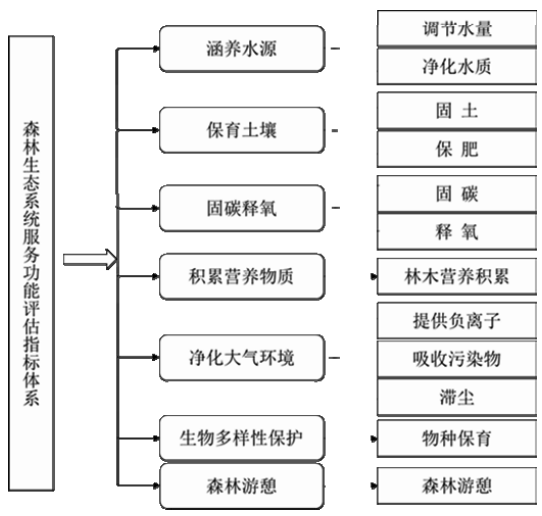

图 2. 云南森林生态价值估算指标体系

文章使用了以下数据用于生态价值计算:
涵养水源价值: TRMM月度降水数据 (2001-2012 年); MODIS产品MOD13A3 月NDVI数据; MODIS 产品MOD16A3年蒸散数据; DEM高程数据; 云南境 内地面气象站2001-2012年年降水数据; 不同大类林 地中地表径流系数。

保育土壤价值: $1: 100$ 万中国土壤类型图; 有无 林地土壤侵蚀差; 不同土类的土壤容重和养分含量。

固碳释氧价值: IBIS模拟的云南植被碳库和土壤 有机碳库; MODIS产品MOD17A3年NPP栅格数据。

积累营养物质价值：MODIS产品MOD17A3年 $\mathrm{NPP}$ 栅格数据; 不同大类林木氮、磷、钾养分含量平 均值 ${ }^{[7,8]}$ 。

净化大气环境价值: 不同大类林地提供负离子、 滞尘、以及吸收二氧化硫、氟化物、氮氧化物的能力 ${ }^{[9]}$; 不同大类林木高均值（阔叶、针叶林取 $20 \mathrm{~m}$, 竹 林取 $10 \mathrm{~m}$ )。

生物多样性保护价值: 云南森林生物多样性保护 功能价值。

游悡价值：云南森林公园名录; 《中国林业统计 年鉴》。

\section{2. 森林经济价值计算}

在进行森林火灾的经济损失评估时, 对于本身具 备商品特征且已形成交易市场的林木、林副产品等的 价值评估最基本的方法是市场法，依据此方法计算的 价值损失总额是损失量与相应商品市场价格的乘积。 而对于木材、木制品等的损失估算, 一般使用重置成 本法 ${ }^{[10]}$, 价值损失则是与损失量、相应制品的成本价 或出厂价以及残余价值相关。上述评估方法计算中, 树种、树龄、生长时期、林副产品种类和当年的市场 价格等方面的不同都对应不同的参数值, 将会影响最 终的火灾经济损失计算结果。对单场林火来说, 尚能 够实现对这些信息的调查统计, 但大范围的风险评估 难以实现上述过程。因此, 文章选择了林业年总产值 来衡量森林的经济价值。林业产业总产值较为全面的 反映了森林产业生产活动和在相关服务活动中的价 值, 并以货币形式表现出来。并且产值是已经在实际 经济活动中创造出的价值, 可以更好的区分出森林是 以创造经济效益为主要目标还是以实现生态保护为 存在价值。本文中以县为单位, 县域内单位面积森林 产值作为该县内森林单元的单位面积经济价值。

将生态价值与经济价值计算结果相加, 即得到了 基于生态和经济价值的云南森林单位面积总价值分 布图(图3)。 
Risk Analysis and Crisis Response in Big Data Era (RAC-16)

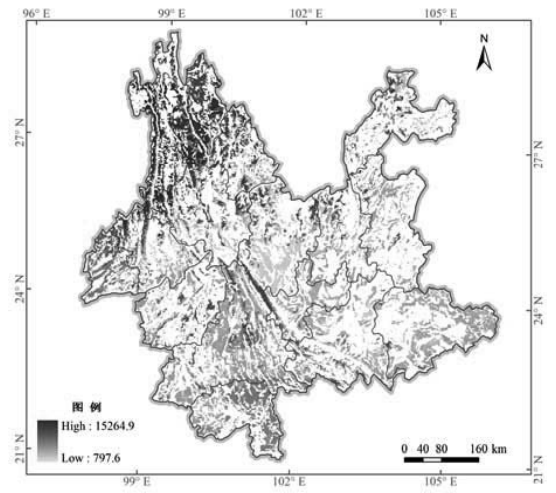

图 3. 云南森林单元总价值分布

\section{4. 森林火灾敏感性与仿真事件分配}

随机森林 (Random Forest, RF) 是Breiman在2001 年发表的一种机器学习算法 ${ }^{[11]}$ 。本文基于随机森林方 法计算了森林火灾敏感性值, 计算方法如图4所示。 大量国内外已有研究表明, 森林火灾发生与气候条 件、地形条件、植被属性、人口因素等多方面因素有

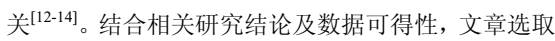
了上述四个因素相关的影响变量共 57 个。其中, 气候 因素包括: 平均温度、平均地表温度、最高温度、最 低温度、降水率、比湿、最大比湿、最小比湿、风速 9 个变量在相应句的平均值及日、小时的最大、最小 值, 降水量旬平均值和日降水量旬最大、最小值, 以 及月份和季度; 地形因素包括: 海拔和地表粗䄳度; 植被因素包括: 森林面积、植被类型、林地起源; 人 口因素包括: 所在地区人口密度。

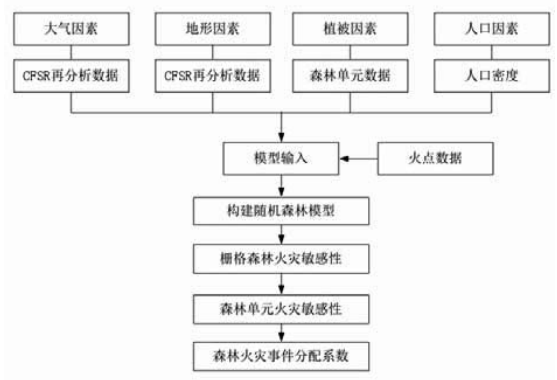

图 4. 云南森林火灾敏感性及分配系数计算流程

模型输入的火点数据是来自数字化的 2002 至 2010年的我国风云卫星火点图, 每10天一期, 共423
期。气象数据和地形数据, 选择使用美国国家环境预 报中心 ( National Centers for Environmental Prediction, NCEP) 2002-2010年的CFSR再分析数据 (Climate Forecast System Reanalysis), 数据分辨率为 $0.313^{\circ}$ 。植被数据通过对 《中国天然林分布图》和 《中国人工林分布图》数字化获得。人口因素中应用 的代表变量是森林所在地区的人口密度, 采用了云南 省统计年鉴数据, 将各县人口除以县域面积得到各县 的人口密度。随机森林建模使用 $\mathrm{R}$ 软件, mtry（每个 非叶节点分枝时使用的特征变量数) 和ntree (随机森 林中的决策树数量) 参数均采用程序的默认值, 其中 $\operatorname{mtry}=\operatorname{int}(\sqrt{ } n)=7(n$ 为特征变量总数 $), n t r e e=500$ 。建 模在 $0.313^{\circ}$ 分辨率下进行, 最终得到 9 年的森林格网 数据, 共 139320 个样本, 无森林火灾样本136706个, 有森林火灾样本2614个。为保证模型对林火发生的预 测准确性, 学习过程中使2614个有森林火灾样本全部 进入, 随机抽取 2091 个非火点。最终, 根据OOB数 据进行模型准确度估计, 模型整体准确率为 $86.04 \%$, 有森林火灾格网预测准确率达到了 $87.83 \%$ 。

将所有森林火点样本与模型得到的敏感性图叠 加 (图5), 发现林火敏感性分布与历史火点分布类似, 因此将敏感性值作为林火灾害仿真事件的分配依据 是较为合理的。

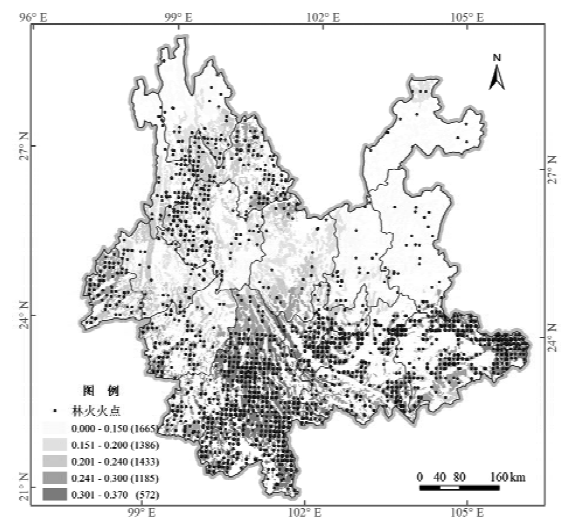

图 5. 云南森林火灾敏感性图

将各森林单元的林火敏感性进行归一化处理得 到单元的林火事件分配系数。对于重、特大林火事件, 将分配系数进行累加, 然后由计算机在 $(0,1)$ 上按 照均匀分布生成随机数, 根据随机数所落到区间对应 的森林单元决定被分配火灾事件的第一次分配结果。 当第一次分配结束后, 需要对分配结果进行合理性判 定, 即该森林火灾事件受损面积是否小于其被分配到 
的森林单元的面积。对两者进行比较, 当火灾面积小 于森林单元面积时, 分配结果即为最终结果, 否则对 该火灾事件进行重新分配, 直至满足合理性判定条 件。对于一般火灾事件, 将森林单元分配系数乘以云 南省该年一般火灾总次数, 再乘以一般火灾期望面积 损失, 得到该单元该年一般火灾面积损失。各森林单 元各年森林火灾总受灾面积可由下面公式获得:

$$
S_{i k}=49.5 N_{i k}+\sum S_{i k \text { 垂大 }}+\sum S_{i k \text { 特大 }} \text { (1) }
$$

式中, $S_{i k}$ 为第 $i$ 个森林单元第 $k$ 年总的林火受灾

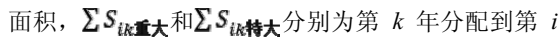
个森林单元的所有重、特大森林火灾面积总和, 49.5 公顷为单次一般森林火灾的期望面积损失。

在得到各森林单元每年的火灾受灾面积总和后， 将其乘以相应森林单元的单位面积经济价值和生态 价值总和, 即可得到各森林单元每年森林火灾期望价 值损失。这一过程如图6。

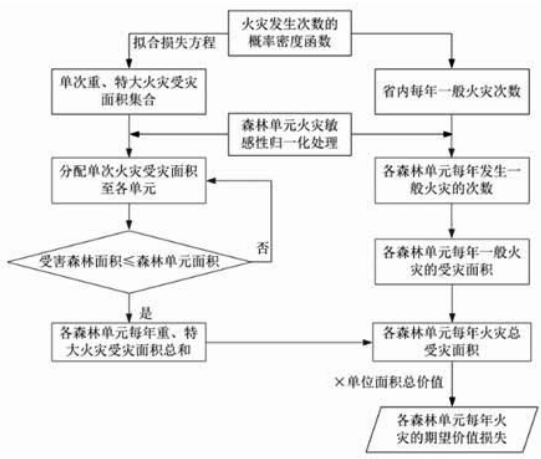

图 6. 林火事件仿真流程

致灾因子仿真过程中应用的随机火灾事件取自 方伟华等在2011年发表的《综合风险防范 数据库、 风险地图与网络平台 $\rangle^{[15]}$ 中生成的 1000 年森林火灾仿 真数据库, 包括云南省1000年一般火灾次数和重、特 大森林火灾事件。

\section{5. 云南森林火灾风险评估结果}

统计各森林单元 1000 年每年林火价值损失, 将单 元内若干年一遇的森林火灾所可能造成的森林总价 值的损失制成森林火灾年遇型风险图。图7、图8分别 为各承灾体森林单元十年一遇、百年一遇的年遇型风
险, 由图能够看出, 云南十年和百年一遇森林火灾生 态与经济总价值期望损失分布大体一致, 为了进一步 观察这一区域分布特征及构成区域间差异的影响因 素, 在此选择云南十年一遇森林火灾风险情况作一详 细分析 (图9)。

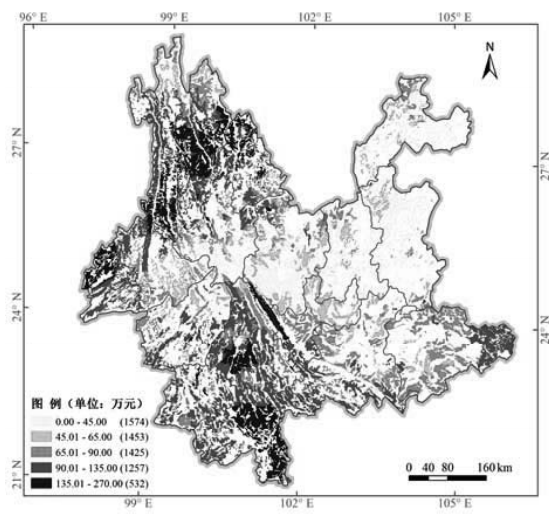

图 7. 云南十年一遇森林火灾总价值损失分布

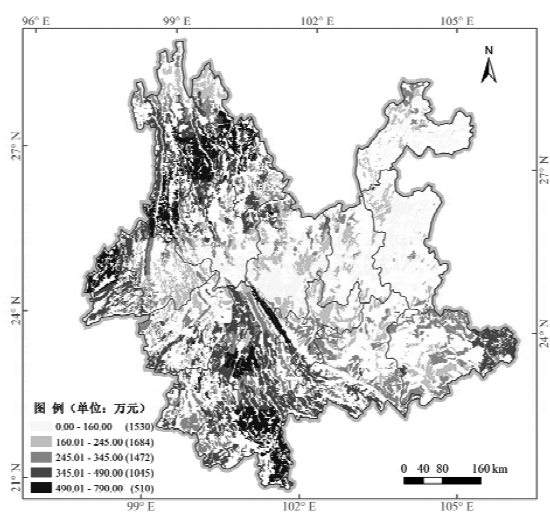

图 8. 云南百年一遇森林火灾总价值损失分布

由图9中 (a)、(c) 可知, 滇南地区整体高于滇 北, 滇南地区以滇西南期望面积损失大, 属全省风险 较高地区。滇北则以 “三江并流” 区域东南部期望面 积损失较高, 是全省风险中等地区。而在综合考虑森 林单元林火敏感性 (a)、单位面积的总价值 (b) 和 期望面积损失 (c) 后, 图 (d) 中的全省森林火灾风 险分布格局发生了变化。

具体来看, 云南中北部及东北部地区整体期望损 失较低, 这里的大部分地区是林火敏感性较低且总价 
Risk Analysis and Crisis Response in Big Data Era (RAC-16)

值处于中低水平, 因此两者综合森林火灾风险较低。 “三江并流” 区域东南一线是损失较高的分布 区, 该区域在林火敏感性图以及面积分布图中多属中 等火灾敏感性地区，但是有着极高的生态价值，因而 相叠加表现的出林火价值损失较大。对于这一地区, 虽然林火事件发生的风险在云南境内只是一般水平, 但火灾造成的生态价值损失风险却不可忽视, 尤其一 旦重、特大森林火灾发生，生态恢复所需的时间和金 钱耗费都将巨大。因此, 更应加强该区域的林火灾害 防灾减灾及防护措施。

滇西南地区也是森林火灾期望损失较高的地区, 这一区域森林总价值在全省位于中等水平, 而林火敏 感性却是极高的, 最终两方面共同作用呈现出该地区

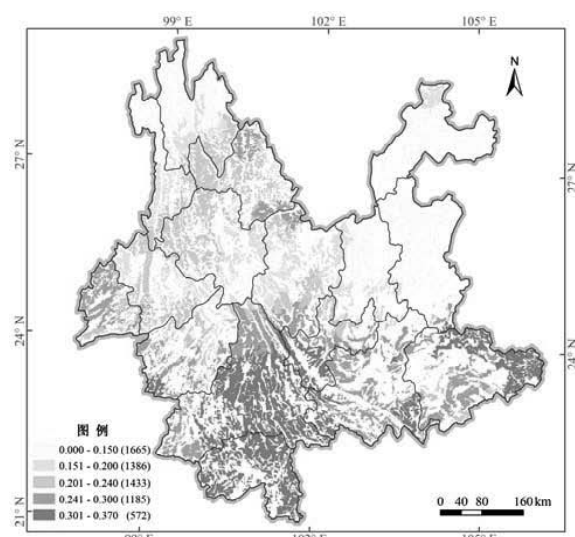

(a) 云南森林单元火灾敏感性分布

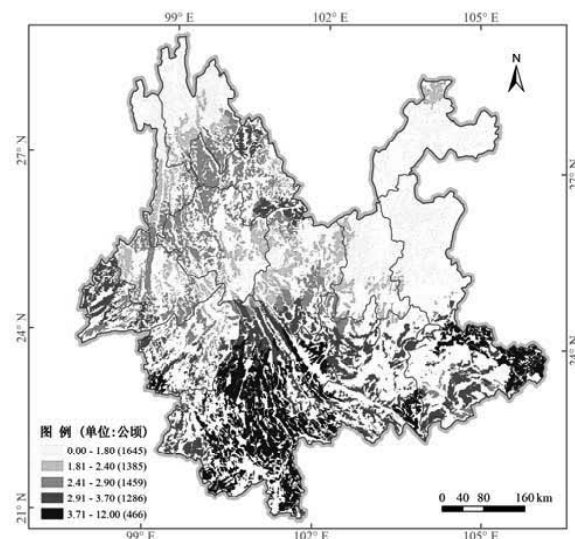

(c) 云南10年一遇森林火灾面积损失分布
较大的森林火灾风险。注意到滇西南地区是生态价值 中等、经济价值中等偏高的地区, 部分市县还有较高 的林业产值生态价值比, 因此该区域在应对森林火灾 风险时, 需要多方面考虑火灾事件发生风险、生态损 失风险和对林业经济的影响。一方面, 应注意森林防 火工作和灾害应急响应, 滇西南地区属林火敏感性很 高的地区, 气候因素 (温度、湿度等) 在森林火灾预 测中影响较大, 因此要做好对高温、干旱等森林火灾 易发天气的准确预报以及林火的灾前预防。另一方 面, 频发的森林火灾对林业经济会产生不利影响, 所 以当地林区在发展林业产业的同时, 更应注重火灾影 响下森林经济损失风险分散与转移机制的建立和完 善。

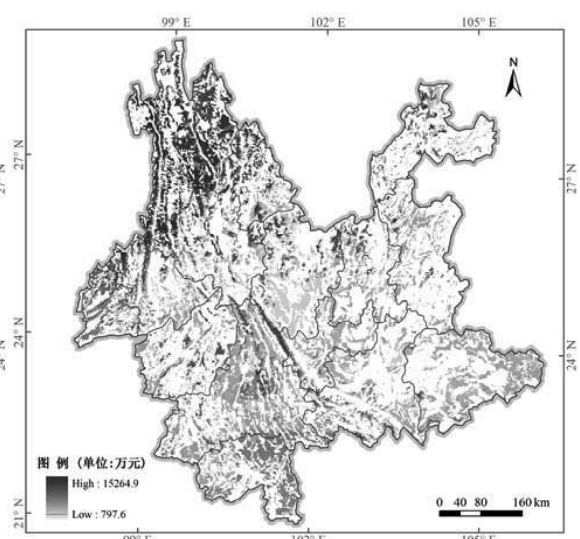

(b) 云南森林单元单位面积经济与生态总价值分布

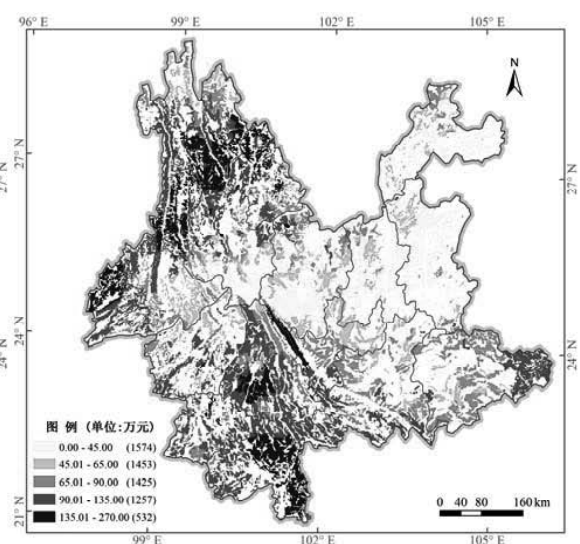

(d) 云南10年一遇森林火灾价值损失分布

图 9. 云南十年一遇森林火灾风险对比 


\section{6. 结论与展望}

本文在综合以往林火相关风险研究的基础上, 结 合机器学习与蒙特卡洛仿真方法, 将基于随机森林方 法计算的林火敏感性用于改进随机火灾事件的分配 过程, 并以量化的森林生态与经济价值作为风险评估 结果的表达, 实现了以云南为例基于生态与经济价值 的森林火灾风险评估, 主要结论如下:

1）基于随机森林方法计算的林火敏感性与火灾 事件分布相一致, 将林火敏感性作为随机火灾事件的 分配依据, 能够实现事件更合理的分配, 从而有效提 高评估精度。

2) 森林具有重要的生态、经济功能, 将量化的 森林生态及经济价值纳入森林火灾风险评估过程, 体 现了灾害风险评估中对承灾体的综合评价, 因此在风 险评估中加入森林价值十分必要。

3）云南年遇型林火风险分布呈现一定的区域特 征。森林单元火灾敏感性、单元面积以及森林总价值, 分别在特定森林单元内林火事件的易发程度、最大可 能的林火等级和林火事件造成的损失三个方面对林 火风险起到决定性作用。尽管有些地区最终呈现出的 期望价值损失水平类似, 但其背后的主导因素却有所 差异, 因此对于不同类型的高损失风险地区, 森林火 灾风险防范工作也需要有针对性。

4）对于云南政策性森林火灾保险的发展, 本文 中云南森林单元在生态价值、经济价值、林火敏感性 以及火灾期望价值损失上呈现出的地域性特征, 能够 在差异化费率的制定、对不同功能森林的补贴水平确 定提供一定的参考和借鉴。

文章仍存在一些问题可以进一步讨论, 如数据精 准程度的提高; 按火灾类别分别计算林火敏感性用于 仿真事件分配; 考虑林火发生后森林价值的损失比例 等。

\section{7. 参考文献}

[1] Tian X, Shu L, Zhao F, et al. Future impacts of climate change on forest fire danger in northeastern China, Journal of Forestry Research, 22(3): 437-446, 2011.

[2] Weinstein D A, Woodbury P B, Review of Methods for Developing Probabilistic Risk Assessments, 2010.

[3] Li X, Wu W, Lv D, et al. Research on Risk Assessment and Regionalization of Forest and Grassland Fires, Journal of Risk Analysis and Crisis Response, 2(1): 69-77, 2012.

[4] 白冬艳, 翟印礼, 陈绍志, 等. 基于自回归移动 平均(ARMA)模型的森林火灾预测, 林业实用技
术, (06): 11-14, 2013.

[5] 金旭, 廖善刚, 基于信息扩散理论的福建省森 林火灾风险评估, 河南大学学报 (自然科学版), (02): 190-195, 2014.

[6] 国家林业局. LY/T 1721-2008. 森林生态系统服务 功能评估规范, 2008

[7] 孙鸿烈等. 中国生态系统定位观测与研究数据 集。森林生态系统卷。云南哀牢山站： 2003-2007，北京：中国农业出版社, 2011

[8] 孙鸿烈等. 中国生态系统定位观测与研究数据 集。森林生态系统卷。云南西双版纳站： 1998-2006, 北京: 中国农业出版社, 2010.

[9] 刘盈盈, 贺红早, 张玉武, 等. 黔东南州森林净 化大气环境价值评估, 贵州科学, (05): 108-110, 2013.

[10] 袁桂萍, 魏彩完, 森林火灾损失评估方法探究, 广西财经学院学报, (06): 68-72, 2013.

[11] Breiman L. Random forests, Machine learning, 1(45): 5-32, 2001.

[12] 宋卫国, 马剑, Satoh K, 等. 森林火险与气象因 素的多元相关性及其分析, 中国工程科学, (02): 61-66, 2006

[13] 宋卫国, 王健, K S, 等. 人口密度对森林火灾 发生频率的影响, 火灾科学, (01): 1-5, 2005.

[14] Ganteaume A, Camia A, Jappiot M, et al. A Review of the Main Driving Factors of Forest Fire Ignition Over Europe, Environmental management, 51(3): 651-662, 2013.

[15] 方伟华, 王静爱, 史培军, 等. 综合风险防范 数 据库、风险地图与网络平台, 北京: 科学出版社, 2011. 